\title{
Research on Chinese University Students’ Intercultural Communication Competence
}

\author{
WANG Jian-ying \\ Qingdao University of Science and Technology, Qingdao, China
}

\begin{abstract}
Problems existing in the acquisition process of ICC (intercultural communication competence) of Chinese English majors motivated the author to investigate the Icc (intercultural communication consciousness) of Chinese English majors. A questionnaire was administered to 116 students at the School of Foreign Languages Studies, QUST (Qingdao University of Science and Technology). The participants’ Icc status was established by their scores on the questionnaire, the questionnaire data was grouped and processed by SPSS (Statistical Product and Service Solutions) 19.0. It was found that most Chinese English majors have weak Icc, tending to equate English language proficiency with ICC. The study identified the possible causes of this. On the one hand, current English language teaching and learning in China is knowledge-centered and exam-oriented, not attaching great importance to cultural education in language teaching. On the other hand, the limited cultural teaching that is carried out stresses cultural facts and differences without enlightening students as to the reasons for these differences.
\end{abstract}

Keywords: ICC (intercultural communication competence), Icc (intercultural communication consciousness), Chinese English majors, cultural education

\section{Introduction}

ICC (intercultural communication competence) engages directly with communicators' language-and-culture knowledge as an integrated whole. High degrees of intercultural communication competence involve communicators' commitment to undergoing intercultural challenges. These challenges are the reduction of culture shock and the development of their cross-cultural learning experience. Recognizing the reality of Chinese university students' intercultural communication, university teachers in China should value quality over quantity in intercultural communication. They should choose intensive immersion cultural experiences, allowing individual students to work at understanding an intensive sampling of cultures in order to improve their intercultural communication competence.

\section{Research Background}

With the development of globalization, ICC has become a pressing need, and this research is based on meeting this need. The author asserts that ICC should be the ultimate goal of college English teaching in China, but the present methodology is far from effective and far from satisfactory.

WANG Jian-ying, associate professor, School of Foreign Language Studies, Qingdao University of Science and Technology. 
As a major component of ICC, Icc (intercultural communication consciousness) plays a significant role. Therefore, the study of the acquisition of Icc is of importance for college English teaching and learning in China.

With the development of information technologies and communications, globalization is an ongoing process. Students' isolation from foreign cultures has become outdated, with interdependent cooperation and development now being the trend in the contemporary world. Globalization does not, however, mean convergence or unification. It is, rather, the reconciliation and mutual acceptance of people from different countries and with different cultural backgrounds.

In China, sensitivity to cultural differences and ICC has become a pressing need. In order to be attuned to the 21st century, the major teaching objective of English teaching in Chinese colleges should shift from cultivating language proficiency to cultivating ICC.

\section{Problems With the Acquisition Process}

The dilemma confronting Chinese English majors in the acquisition of Icc can be generalized as follows: Although at the cognitive level, most English majors have an open mind and respect foreign cultures, they engage in few intercultural interactions because of a lack of intercultural confidence. They can be observant in interaction but they cannot enjoy themselves in interaction. Several difficulties have lead to the current predicament.

The first difficulty is to do with thinking and awareness. Many Chinese English major students have only a vague idea of the cross-cultural or inter-cultural concept. They are not aware that their learning and practice involves intercultural communication. Only a few have begun to realize the significance of cultural factors in intercultural communication. That is to say, most English majors seldom combine language learning with intercultural communication, and they focus on English learning and improving English proficiency. The author found that most English majors identify themselves as English learners rather than intercultural communicators. In addition, some of their teachers make them feel that they should be fully immersed in English and its culture so as to master it. Few English teachers mentioned the concept of conflicts between Chinese cultures and the cultures of the English-speaking countries. They only put stress on introducing different aspects of English cultures.

The second difficulty is concerned with learning. The English language learning of most students is exam-oriented and knowledge-centered. The main driving force for their learning is the course exam. If the teacher is very strict and requires a lot of them, they will take the course seriously and make more preparations for the course. They benefit from the strict requirements and difficult exams, but the benefit is not enough to encourage them to actively learn. Although most teaching materials and text books are filled with descriptions of different aspects of English culture, the students pay more attention to the language of the descriptions. They care about the novel uses of some words or the new expression of an idea. Once they can adopt the new words in their writing or speaking, they feel their studies are effective. However, most of them cannot persist in such kind of accumulation, since exam-oriented learning is a for the most part boring.

The third difficulty is a lack of practice. Students at the medium level do not participate in much intercultural communication. They are willing to communicate with foreigners from English culture but they lack intercultural confidence and are afraid of making mistakes in communication. Their intercultural 
experiences center on communicating with their foreign teachers. Due to the lack of intercultural experiences, some participants do not have an objective and comprehensive attitude to English-speaking culture or its people. Some interviewees admitted that they have a prejudice against English language culture because of the actions of some English-speaking countries in international affairs. In addition, in their limited communication with foreigners, those foreigners left bad impressions.

\section{Characteristics of the Icc Acquisition Process}

The author analyzed the causes of the difficulties and problems mentioned above using questionnaire data and in-depth interview data. The analysis of these data revealed the following characteristics of the current cultural education in Chinese universities.

\section{The Characteristics of Cultural Teaching for English Majors}

The current situation of intercultral communication teaching for English majors in China requires teachers to pay more attention to the characteristics of cultural teaching for English majors.

(1) Many courses in the English major involve so-called cultural education, such as "An Outline Introduction to English Speaking Countries”, “An Introduction to European Culture, English Literature, American Literature”, and “Cross-Cultural Communication”. However, such information does not provide a perspective on the everyday culture of ordinary English speakers in the English speaking world. For the most part, Chinese students only get a picture of foreigners' life, lifestyle, family life, and interpersonal relationships from movies, TV programs, novels, etc., which seldom reflect the day-to-day life of ordinary people.

(2) Teaching materials focus on cultural knowledge, especially typical and concrete cultural knowledge. The comprehensive outline of English culture and the deep level of the culture, like the values, worldview, and religion, are little involved in teaching. Students master some points of English culture but do not acquire a systematic and in-depth knowledge of the culture.

(3) Generally, the teaching objective of the courses is either to equip students with the basic knowledge of English culture or to train communication skills in certain intercultural occasions. Such teaching is simply pumping knowledge into students' heads rather than enlightening them. Very few teachers attempt to cultivate students' cultural awareness or capacity for introspection, and perhaps few teachers have the willingness or even ability to do so.

(4) Chinese teachers of English major students usually focus on introducing different aspects of English culture and expect the students to be fully immersed in the culture. Many teachers share their own experiences of cultural shock abroad. However, the teachers do not then lead the students to think about the underlying causes of these shocks, thereby allowing students to form an objective attitude towards English culture. When there are cultural conflicts Chinese culture is invariably "right” and English culture is invariably "wrong” (in fact neither is right nor wrong, they are simply different).

(5) The quality of foreign teachers is not satisfactory in teaching language and culture. Many foreign teachers in Chinese colleges cannot adopt suitable teaching methods and concepts in accordance with the Chinese situation. They either underestimate students' learning ability, teaching some simple and concrete knowledge points without referring to the textbook, or teach strictly according to the book. 


\section{The Characteristics of Cultural Learning}

Many Chinese universities are heavily biased toward different cultures' uniformity over their diversity. To achieve balance between uniformity and diversity, learners need to be aware that sameness is always easier to accommodate than difference; honoring cultural diversity does not imply a lack of clear beliefs and strong values. University teachers, who want to give each student an opportunity to reach his/her individual potential, need to be aware and appreciate each student's cultural learning characteristics. At present, most English majors have the following cultural learning characteristics.

(1) Most English majors focus on improving English skills, listening, speaking, reading, and writing. These are also the teaching objectives of many basic courses in English majors. These skills are practical and useful, especially in looking for jobs and most students also equate English proficiency with communication competence.

(2) The driving force for students' learning is examinations, in particular for English Majors the TEM-4 (Test for English Majors Band Four) and TEM-8 examinations. These course exams are the primary motive for them to learn so they spend much time in accumulating cultural knowledge to pass the exams. In their minds, English knowledge seems like computer science. Few students pay attention to the cultural differences or think about the underlying causes of these differences.

(3) Attitudes toward English culture and people from English-speaking countries vary from student to student. In the questionnaire, when presented with statements concerning respect for different cultures, most students chose "agree" or "strongly agree". As interviewees, however, they demonstrated conflicting attitudes. It was evident that they agree to respect cultural differences at the cognitive level but they do not accept such differences at the affective level.

(4) Many English majors have little Icc. They identify themselves as English learners and seldom combine English learning with intercultural communication. The interview also demonstrated this point. Interviewees said that they had no idea of the cross-cultural or inter-cultural concept until taking the course on cross-cultural communication.

\section{Main Findings of the Study}

On the basis of the questionnaire survey and in-depth interviewing, the author studied the acquisition of Icc of Chinese English majors from the perspectives of learning and teaching. Some of the major findings are summarized here.

As has been mentioned above, the Icc of most Chinese English majors is weak. Most have only a vague idea of the cross-cultural or intercultural concept. They have not realized the significance of culture in English learning. They prefer to identify themselves as English language learners and seldom relate English learning to culture learning.

Secondly, in light of the cultural learning of Chinese English majors, the following points need special attention: (1) Without proper guidance in cultural learning, most English majors simply focus on improving their English language skills. They know little about intercultural communication and tend to equate English language proficiency with ICC; (2) English learning is mainly exam-motivated. Students learn what they need to learn to pass the exam, they do not try to systematically absorb and understand the culture and diversity of the 
English-speaking world; and (3) For the most part, English majors participate in limited intercultural communications and do not have a comprehensive and objective impression of the English culture and its people. Moreover, most English majors lack interaction confidence when communicating with foreigners.

Finally, in light of culture teaching in Chinese colleges, the following features or problems are of concern: (1) Although many courses involve English culture, the teaching of these courses still puts emphasis on the language level. The introduction of culture serves only as background information; and (2) Many English teachers provide basic knowledge or training in communicative skills and strategies but ignore the cultivation of culture quality. They seldom enlighten students about the underlying structure of English culture. They fail to lead students to think about the fundamental causes of these differences.

\section{Implications of the Study}

On the basis of the analysis of the questionnaire and in-depth interview data, the author concluded that there are some problems in the current acquisition of Icc of the English majors in Chinese colleges. Some important implications of the research are generalized as follows.

(1) Cultural education must be given more attention in EFL (English as a Foreign Language) and such emphasis should be carried out in daily teaching and learning. Both teachers and students must be aware of the significance of culture in English learning and in communication. Some activities concerning different themes in English culture should be held often, for example, seminars, debates, lectures, and movies appreciation.

Students should be encouraged to meet and interact with English-speaking foreigners. If this is not practical or possible, the universities should at least arrange their own social events at which students can meet and communicate with a diversity of English-speaking foreign teachers.

In the beginning, students might be compulsorily obliged to engage in these activities, however, persistence is the key to achieving results.

(2) English teaching objectives should shift from training English skills to cultivating cultural quality. Teachers should guide students to think beyond the superficial cultural differences. There is a fundamental need to enlighten students about the underlying causes of cultural differences, such as cultural values, worldviews, and geopolitics. Abstract and profound thinking should be written down in the form of reports and presentations, and each student should be offered the opportunity of expressing their thoughts and viewpoints.

(3) Students should be encouraged, indeed required, to participate in intercultural communications. After each communication, they can record their good performances, mistakes, and confusing points. Through discussing with classmates and teachers, they can solve these concrete problems and make progress. Such constant practice aims to improve the interaction confidence and attentiveness of the students in intercultural communications. Encouragement and perhaps some pressure will be necessary.

(4) Practical measures should be taken to help students form open minds and objective attitudes to English-speaking countries and culture. In cultural education, the discussion and analysis of current international affairs happening in English-speaking countries should be included, and students must present their own ideas and thoughts in the discussion. Such discussion and analysis will lead students thinking beyond prejudice or superficial impressions of an event. It will cause them to examine the deep cultural and political causes. Thus, students can really respect different cultures and shed any prejudices they might have in intercultural communication. 


\section{Conclusions}

In intercultural communication teaching and learning, the uniformity and diversity of cultures are equally important. Chinese students need a large amount of cultural knowledge. Cultural differences should be recognized in conversations and appreciated in intercultural communication to make the uniformity and diversity of cultures more flexible and accessible. People should avoid cultural confrontation to achieve favorable communication.

\section{References}

Bennet, M. J. (1998). Intercultural communication: A current perspective. In M. J. Bennet (Ed.), Basic concepts of intercultural communication: Selected readings. Yarmouth, Canada: Intercultural Press.

Kim, Y. Y. (1997). Interethnic and intra-ethnic communication. In N. Jain (Ed.), International intercultural communication annual. Falls Church, V.A.: Speech Communication Association.

Kincaid, D. L. (1988). The convergence theory of intercultural communication. In Y. Y. Kim, \& W. B. Gudykunst (Eds.), Theories in intercultural communication. Newbury Park, C.A.: Sage.

Lusting, M., \& Koester, J. (1996). Intercultural competence: Interpersonal communication across cultures (2nd ed.). New York: Harper Collins College Publishers.

Spitzberg, B. H., \& Cupach, W. R. (1984). Interpersonal communication competence. Beverly Hills, C.A.: Sage.

Wiemann, J. M., \& Backlund, P. (1980). Current theory and research in communicative competence. Review of Educational Research, 50, 185-199. 